\title{
REFLEXIONES SOBRE LA FUNCIÓN SOCIAL DE LA HISTORIA: HOBSBAWM, THOMPSON Y KOCKA
}

\author{
Reflections about social funcion of history: Hosbawm, Thompson and Kocka
}

\author{
Álvaro Carvajal Castro (carvajal@usal.es) ${ }^{1}$ \\ Isaac MArtín Nieto (isaacmartin@usal.es) ${ }^{2}$ \\ Alejandra SÁnchez POLO (asanpol@usal.es) ${ }^{3}$ \\ Universidad de Salamanca
}

Fecha de recepción: 6-III-2011

Fecha de aceptación: 13-IV-2011

RESUMEN: La historia cuenta cada vez con más medios para su divulgación. Precisamente por ello, debemos preguntarnos cuál es y plantearnos cuál debería ser la función social que cumple el conocimiento histórico que se transmite a la sociedad. Para ello, partimos de las reflexiones de E. Hobsbawm, E.P. Thompson y J. Kocka, tres historiadores que proceden del ámbito historiográfico de la historia social y que, dada su práctica historiográfica y vital, resultan claves para desarrollar esta problemática.

Palabras clave: historiografía, historiador, responsabilidad, Hobsbawm, Thompson, Kocka.

AвSTRACT: Nowadays we have more ways than ever to disseminate historical knowledge. Because of that, it is important that we carefully consider what is, and what should be, the social function that historical knowledge fulfills. This article considers the issue from the point of view of the works of E. Hobsbawm, E.P. Thompson and J. Kocka, three historians within the realm of social history who, given their historiographical practice and life story, are key in our understanding of the problem.

Keywords: historiography, historian, responsibility, Hobsbawm, Thompson, Kocka.

1 Beneficiario de una ayuda del programa FPU del Ministerio de Educación.

2 Beneficiario de una ayuda para la FPI de la Universidad de Salamanca.

3 Beneficiaria de una ayuda PIRTU de la Junta de Castilla y León. 
"Uno de los fenómenos sociales más notables de nuestro tiempo constituye lo que podríamos llamar el proceso de democratización de la cultura"4. Con estas líneas comenzaba el arqueólogo Juan Maluquer el prólogo de un libro introductorio a la arqueología, hace ya casi cuarenta años. En las últimas décadas, varios factores han contribuido a expandir aún más las posibilidades de difusión y de acceso a los distintos fenómenos culturales. Los cambios han afectado, como no podía ser de otra manera, a la historiografía 5 . Sin embargo, esto no parece haber ido acompañado de la extensión de una auténtica conciencia histórica, entendida como una conciencia crítica sobre la relación de nuestras sociedades con el pasado y como parte integrante de la acción social en nuestro presente. A simple vista contemplamos la extensión de la historia anécdota, de una historia que, en definitiva, se ve sometida a las necesidades de legitimación de la sociedad actual. Pero, en la medida en que participa del juego de relaciones de poder como argumento del discurso político, como pieza constitutiva de identidades colectivas o como instrumento para naturalizar esas mismas relaciones de poder, una mayor difusión de la historia no puede ser tomada, per se, como algo bueno.

La historiografía parece ver reducido su hueco a la aportación de datos que no se integran, a través de la reflexión, en la estructura de una explicación de los procesos de transformación de las sociedades. El pasado se percibe como un continum de acontecimientos y fechas sin relaciones profundas entre sí. Al mismo tiempo, se ve desvalorizada por la creencia de que no aporta un conocimiento inmediato y práctico a la sociedad. Un ejemplo actual de la pérdida de importancia de las ciencias humanas es la eliminación de la licenciatura de Humanidades de los planes de estudios universitarios del sistema educativo español ${ }^{6}$; o que, en el informe PISA ${ }^{7}$, referencia a nivel internacional sobre la calidad de los sistemas educativos de casi cien países, ni siquiera se evalúen las competencias adquiridas por los adolescentes en las materias relacionadas con las ciencias humanas.

Los medios de comunicación han influido notablemente en la

4 MALUQUER DE MOTES, J., "Prólogo", en CHILDE, V. G., Introducción a la Arqueología, Barcelona, 1972, p. 5 (la cursiva es nuestra).

5 Siguiendo a ARÓSTEGUI, Julio: La investigación bistórica: teoría y método, Barcelona, 2001, pp. 15-16, en este texto llamaremos historiografía a la disciplina que estudia la historia, considerando a ésta como la entidad objeto de estudio de aquélla.

6 Sobre la necesidad de que los procedimientos enseñados en licenciaturas y grados, tanto de humanidades como de ciencias, sean utilitarios de cara a la incorporación al mundo profesional, vid. http://www.queesbolonia.gob.es/dctm/queesbolonia/documentos/ bolonialetrasciencias.pdf? documentId $=0901 \mathrm{e} 72 \mathrm{~b} 8004 \mathrm{c} 353$ [fecha de consulta: 24/01/2011].

7 Para consultar los datos del último informe, elaborado en 2009, vid. http://browse. oecdbookshop.org/oecd/pdfs/browseit/9810071E.PDF [fecha de consulta: 22/01/2011]. 
aceptación y valoración de la disciplina. En gran medida, la historia se ha visto reducida a un elemento de ocio. Los medios audiovisuales la emplean como un reservorio de argumentos y ambientaciones en el que su papel se reduce a la provisión de acontecimientos y a la caracterización más o menos exótica de los personajes ${ }^{8}$. Documentales como Memoria de España, que consiguió una cuota de audiencia importante, son testimonio de que, efectivamente, existe una demanda de conocimiento sobre el pasado por parte de la sociedad española. Incluso sirvió para abrir un espacio de divulgación a historiadores reconocidos?. Lo importante, sin embargo, es que nos preguntemos en qué sentido se orientó esa transmisión de conocimiento. La serie apenas propiciaba algo más que un consumo acrítico de acontecimientos. La narración eclipsaba la argumentación y la explicación histórica. El telón de fondo, debido a la confusión que propiciaba entre historia y memoria, no dejaba de ser el de la instrumentalización política de la historiografía ${ }^{10}$. Fue, por tanto, una demostración de cómo la historia se ha convertido en un bien de consumo inmediato ${ }^{11}$ que contribuye a forjar lo que Hobsbawm llamó la "invención de la tradición"12.

Frente a esta historia que se vende y se divulga, nosotros partimos de una concepción de la historia como proceso de transformación de las sociedades a través de la interacción dialéctica entre la estructura y la acción

8 CARVAJAL CASTRO, A.; DE SOTO GARCÍA, R.; HERNANDO ÁLVAREZ, C., y TEJERIZO GARCÍA, C. "El síndrome de Indiana Jones: la imagen social del arqueólogo", en Actas de las III Jornadas de Jóvenes en Investigación Arqueológica. UAB 5-7 de mayo de 2010, en prensa.

9 La serie fue coordinada por Fernando García de Cortázar, y por los especialistas más renombrados de cada campo, lo que garantizó la corrección de los contenidos a nivel metodológico (vid. HERNÁNDEZ, S., "El documental de divulgación histórica en la televisión española (y 3): La «telehistoria» frente a la «telerrealidad»", Guión actualidad, lunes 12 de febrero de 2007 [http://200.2.115.237/spip.php?article2215. Fecha de consulta: 05/02/2011]). La emisión del documental en su primera emisión, en 2004, fue seguida por una media de tres millones y medio de espectadores. Como reflejo de las controversias de carácter político en torno a la serie histórica, vid. los artículos publicados en El País el 22/01/2004 y el 15/03/2005 (respectivamente, http://www.elpais.com/articulo/Pantallas/ Memoria/Espana/apuesta/Primera/martes/elpepirtv/20040122elpepirtv_2/Tes y http:// www.elpais.com/articulo/Pantallas/Memoria/Espana/finaliza/llegada/democracia/ elpepirtv/20050315elpepirtv 1/Tes?print=1 [fecha de consulta: 08/02/2011]).

10 CASPISTEGUI, F. J., "Más allá de su oficio, el historiador en sociedad", Alcores, 1 (2006), p. 86.

11 Es posible encontrar hasta 8 títulos diferentes de publicaciones periódicas mensuales relacionadas con la Historia en cualquier kiosco: La aventura de la Historia; Historia National Geographic, Clio; Muy interesante. Historia; Medieval; Memoria Historia; Historia de Iberia Vieja; Historia y vida.

12 HOBSBAWM, E., "Introducción. Invención de la tradición”, en HOBSBAWM, E. y RANGER, T. (eds.): La invención de la tradición, Barcelona, 2002, pp. 12 y 19. 
de los sujetos sociales. Pensamos por ello que el historiador, como sujeto social consciente, está obligado a preguntarse sobre las condiciones del contexto en que vive y a considerar sus posibilidades de acción no sólo como ciudadano, sino, específicamente, como agente dotado por su profesión de la capacidad, parafraseando a Vilar, de pensar histórica y críticamente ${ }^{13}$. En definitiva, el historiador debe dar una respuesta a la pregunta: ¿cuál es la función social de la historia y de los historiadores?

Creemos que la oportunidad de participar en un foro como es el II Congreso de Jóvenes Historiadores: Razón, Utopía y Sociedad es el marco idóneo para exponer no sólo una problemática común a la mayoría de ciencias sociales y humanas, sino también para emprender la búsqueda de respuestas y estrategias conjuntas entre quienes nos iniciamos en nuestras carreras científicas. Toda práctica historiográfica, incluso aquella que se dice apolítica, cumple una de las múltiples funciones sociales que la historia puede adoptar. Evitar la manipulación supone un ejercicio de elección consciente del sentido que le queremos dar a nuestra propia práctica historiográfica.

Se trata de un tema historiográfico recurrente, aunque dotado de una personalidad propia según el medio social y académico y según la experiencia de cada historiador. Nosotros hemos dirigido la mirada más allá de nuestras fronteras para proponer una lectura de los planteamientos de tres autores que hicieron explícita su preocupación sobre la función social de la historia: Edward P. Thompson, Eric J. Hobsbawm y Jürgen Kocka. Historiadores que son, a la vez, representantes de dos de las escuelas historiográficas europeas más relevantes de las últimas décadas: el marxismo británico y la historia social crítica alemana. Sus trayectorias profesionales, por tanto, son en cierta medida coincidentes, ya que no sólo mostraron interés por la historia social, sino que también impulsaron el estudio de la historia para el cambio social. Al tiempo, sus recorridos son divergentes, ya que sus respuestas -no sólo intelectuales, sino también vitales- a la pregunta sobre la función social de la historia y el historiador fueron distintas. Comenzaremos, pues, por una exposición de sus ideas, para luego realizar una consideración final propia.

\section{Eric J. Hobsbawm, Edward P. Thompson y el MarXismo británico}

"No es buena señal del camino por donde va el mundo cuando los hombres pierden confianza en el futuro" (Hobsbawm, La historia y el futuro)

Eric J. Hobsbawm y Edward P. Thompson son dos historiadores unidos por un nexo: la tradición historiográfica que se conoce como

13 Vid. VILAR, P., "Pensar históricamente", en Memoria, historia e historiadores, traducido y editado por A. COHEN, Granada, 2004, pp. 67-122. 
marxismo británico ${ }^{14}$. Ambos autores llegaron al estudio de la historia desde un compromiso político que habían comenzado a forjar en su juventud y que se tradujo en su temprana militancia en el Partido Comunista de Gran Bretaña (PCGB). Los dos participaron en el Grupo de Historiadores del PCGB, del que formaban parte historiadores de la talla de Christopher Hill o Rodney Hilton ${ }^{15}$. Los sucesos de 1956 -las revelaciones hechas en el XX Congreso del PCUS y la invasión soviética de Hungría- provocaron el abandono del partido de varios de estos historiadores, entre los que se encontraba Thompson. No así Hobsbawm, quien siguió vinculado al PCGB hasta su disolución en 1991. Thompson, después de abandonar el Partido, siguió llevando a cabo una intensa actividad política. Su labor en el seno del movimiento European Nuclear Disarmament a partir de 1980, de la que se derivó también una importante cantidad de ensayos y artículos, hizo de él una figura de singular relevancia ${ }^{16}$.

Sus trayectorias profesionales tienen también varios puntos en común, aunque difieren en muchos otros. Thompson apostó al principio por la educación para adultos y nunca se vinculó totalmente a una universidad, aunque dio clases como profesor visitante en varias de ellas. En cualquier caso, reclamaba una cierta independencia para los intelectuales -especialmente los socialistas- y abogaba por la creación de grupos alternativos en los que desarrollar el debate y la crítica sobre la historia y la labor historiográfica ${ }^{17}$. Hobsbawm se mantuvo siempre dentro del ámbito académico, primero como profesor del Birbeck College entre 1947 y 1982, y luego como profesor visitante en otras universidades. Para él, la Universidad representaba un espacio de libertad desde el que ejercer la labor crítica ${ }^{18}$, aunque en sus primeros años se encontró en un medio reacio a aceptar los planteamientos del marxismo y en el que, según nos cuenta, tuvo que esforzarse para construir una historiografía basada en el materialismo histórico que pudiera ser aceptada en el ámbito académico ${ }^{19}$. La larga trayectoria universitaria de Hobsbawm se ha traducido en una importante obra historiográfica ${ }^{20}$. La

14 Vid. KAYE, H.J., Los historiadores marxistas británicos. Un análisis introductorio, Zaragoza, 1989.

15 HOBSBAWM, E., "El Grupo de Historiadores del Partido Comunista", Historia Social, 25 (1996), pp. 61-80.

16 Es particularmente famosos su panfleto Protest and Survive. Existen colecciones que recopilan escritos de Thompson, como THOMPSON, E. P., Opción Cero, Barcelona, 1983 o Id., Nuestras libertades y nuestras vidas, Barcelona, 1987.

17 ABELOVE, H.; BLACKMAR, B.; DIMOCK, P. y SCHNEER, J. (eds.), Visions of History, Manchester, 1983, p. 14.

18 HOBSBAWM, E., “¿Qué puede decirnos la historia sobre la sociedad contemporánea?”, en Id., Sobre la Historia, Barcelona, 1998, p. 51.

19 ABELOVE, H. et al. (eds.), op. cit., p. 32. Fruto de una voluntad de entendimiento entre historiadores marxistas y no marxistas fue la fundación de la revista Past \& Present.

20 La obra de Hobsbawm es difícil de sintetizar. Se pueden destacar títulos como Primitive Rebels, Manchester, 1959 y las sucesivas obras sobre el movimiento obrero; The Invention of 
de Thompson, aunque no tan abundante, se distingue por aportaciones tan importantes como su libro sobre la formación de la clase obrera en Inglaterra ${ }^{21}$ o por términos de análisis como el de "economía moral" pesar de sus diferencias, ambos compartieron una continua preocupación por fomentar una historia social crítica en la que la lucha de clases constituyera la principal herramienta analítica ${ }^{23}$.

De entre las nociones que Thompson manejaba, la idea de experiencia es un buen punto de partida para comenzar a reflexionar sobre la posición de los historiadores como actores sociales y sobre el valor de la historia en general. La experiencia constituye un elemento fundamental en la obra historiográfica de Thompson, quien entiende el término como el ámbito en el que se entrelazan la cultura, la práctica y la relación del individuo con la sociedad ${ }^{24}$. La relación entre nuestra experiencia como seres sociales y nuestra experiencia como historiadores necesariamente confluye en nuestra práctica historiográfica. No podemos decir que una determine a la otra y, sin embargo, ambas se encuentran dialécticamente relacionadas. ¿En qué medida nuestra conciencia social se plasma en nuestra práctica historiográfica? O lo que es más importante para el propósito de esta comunicación, ¿̇en qué medida y cómo puede el conocimiento de la historia contribuir a la experiencia del mundo que tienen los sujetos sociales?

Hobsbawm y Thompson coinciden en señalar que una de las

Tradition, Cambridge, 1983, que manifiesta su preocupación por la manipulación histórica en la construcción de identidades; los cuatro volúmenes sobre historia contemporánea; o su interés en el tratamiento directo de la obra de Marx, como ponen de manifiesto su colaboración en la edición de la misma, o, más recientemente, su libro How to Change the World: Tales of Marx and Marxism, Londres, 2011.

21 The Making of the English Working Class, Londres, 1963, marca, para J. Fontana, (FONTANA, J., "E. P. Thompson, hoy y mañana”, Historia Social, 18 [1994], p. 4), el inicio del periodo de esplendor académico de Thompson, que se cerraría con la publicación de y la de The Poverty of Theory, Londres, 1978, fechas entre las cuales aparecieron otros trabajos como Whigs and Hunters: The Origin of the Black Act, Londres, 1975 o Albion's Fatal Tree: Crime and Society in Eighteenth Century England, Londres, 1975. A estos libros debemos sumar otros como, por ejemplo, el que ya había dedicado a William Morris -William Morris: Romantic to Revolutionary, Londres, 1955.

$22 \mathrm{El}$ término fue introducido en THOMPSON, E. P., "The Moral Economy of the English Crowd in the 18th Century”, Past \& Present, 50 (1971), pp. 76-136; y articularía posteriormente el libro THOMPSON, E. P., Customs in Common. Studies in Traditional Popular Culture, Londres, 1991. Editado en español cuatro años más tarde: THOMPSON, E. P., Costumbres en común, Barcelona, 1995.

23 KAYE, H. J., op. cit., p. 7.

24 La experiencia "incluye la respuesta mental y emocional, ya sea de un individuo o de un grupo social, a una pluralidad de acontecimientos relacionados entre sí o a muchas repeticiones del mismo acontecimiento" en THOMPSON, E. P., Miseria de la teoría, Barcelona, 1981, p. 19. 
aportaciones más importantes de la historiografía es que contribuye a desnaturalizar el presente. Hobsbawm ha hecho mucho hincapié en el fenómeno de las identidades particularistas. A propósito del nacionalismo, por ejemplo, señala que el historiador, mediante la práctica de una historiografía crítica, debe deconstruir los mitos en los que se basa la manipulación política de las identidades ${ }^{25}$. Para Thompson, el historiador puede contribuir, por su conocimiento histórico y a partir del "por qué" y del "dónde nos lleva esto" de una sociedad, a cuestionar la pátina de aparente normalidad que se intenta imponer desde el poder ${ }^{26}$. Del mismo modo, ambos tienen en cuenta la responsabilidad que conlleva la práctica historiográfica, en la medida en que el trabajo del historiador puede verse manipulado políticamente con perversas consecuencias sociales ${ }^{27}$.

Esto no supone, en primer término, sino reconocer que la historia se puede trasladar a la acción social; en definitiva, que la historiografía, en tanto que productora de un discurso histórico, cumple una función más que meramente reactiva -la de una crítica que se ejerce sobre los discursos ya construidos- y que tiene capacidad para llevar a cabo una contribución activa a la sociedad. Ahora bien, estas afirmaciones ponen igualmente de manifiesto que la historia no tiene una función única y exclusiva, sino que dicha función dependerá de cómo se construya el discurso y qué pueda aportar a la sociedad según qué sentido se le dé a la interpretación historiográfica y cómo el conocimiento histórico se integre a través de la conciencia histórica en nuestra experiencia en el presente.

En cuanto al cómo de la práctica historiográfica, estos autores fueron firmes defensores de un discurso construido desde una historiografía fuertemente comprometida con los métodos y preocupaciones de la historia social. La aportación fundamental de este tipo de historiografía ya se ha apuntado antes: se sitúa en la base de una conciencia histórica que nos ayuda a darnos cuenta de que el presente no es algo dado. Esta idea tiene un gran potencial, ya que de ello se deriva que el presente no es sino fruto de un proceso histórico inconcluso y que, por lo tanto, se puede trascender. En este sentido, Hobsbawm profundiza en la capacidad de la historia para realizar una aportación a la sociedad y le atribuye la capacidad de predecir. Predicción

25 Vid. HOBSBAWM, E., Naciones y nacionalismos, Barcelona, 1991; HOBSBAWM, E., "El historiador entre la búsqueda de lo universal y la búsqueda de la identidad", Historia Social, 25 (1996), pp. 81-90.

26 "Las personas más peligrosas de todas son las que quisieran hacernos creer que todo es normal -que lo único que tenemos que hacer es seguir como ahora y confiar en ellas para que dirijan las cosas" (THOMPSON, E. P., Nuestras libertades y nuestras vidas, Barcelona, 1985, p. 14).

27 "La cosecha que recogemos en los campos de la historia pueden acabar siendo una forma de opio del pueblo" (HOBSBAWM, E., "El historiador entre la búsqueda de lo universal y la búsqueda de la identidad", p. 89). Thompson lo expresa así: "las palabras irreflexivas cuestan vidas" (THOMPSON, E. P., Nuestras libertades y nuestras vidas, p. 79). 
que, según él lo entiende, consistiría en la capacidad de descubrir "lo que lo seres humanos pueden y no pueden hacer", de determinar los marcos, los límites, la potencialidad y consecuencias de la acción humana; de identificar los elementos viejos y nuevos de la sociedad actual y, en función de ello, de anticipar las consecuencias de las tendencias observables en la sociedad actual $^{28}$. En un sentido similar, Thompson ve también en la conciencia histórica una herramienta crítica mediante la que, además de responder al "por qué" y al "adónde" de una sociedad, nos permite comprender "las posibilidades que hay dentro de las personas", atendiendo a la necesidad de reconocer nuestra capacidad de acción, individual y colectiva, en el presente en que vivimos ${ }^{29}$. Este énfasis en las relaciones causales y en la capacidad de acción de los seres humanos reduce la indeterminación del futuro y enfatiza la contingencia del proceso histórico, al tiempo que sitúa en el presente la responsabilidad de la producción de las condiciones sociales futuras.

En cuanto al sentido que se le puede dar a esta aportación de la historia, ambos autores reconocen la legitimidad de una valoración del proceso histórico en nuestros propios términos, valoración que no puede ni mucho menos influir en el análisis de su problemática específica, pero que contribuye a hacer su estudio significativo para nosotros ${ }^{30}$. Es muy importante tener en cuenta, como señala el propio Thompson, que la relación entre nuestra experiencia social, que antecede al estudio propiamente histórico, y nuestra práctica historiográfica no es inmediata ni, como Hobsbawm nos recuerda, se puede someter a las exigencias de la política ${ }^{31}$. Por otro lado, si invertimos los términos de este planteamiento, deberemos considerar también que la relación entre nuestra práctica historiográfica y nuestro compromiso social no es tampoco inmediata, lo que nos remite de nuevo al problema de cómo la conciencia histórica se integra en la acción social. Esto, que tan problemático nos resulta cuando realizamos el planteamiento desde la propia historiografía, es precisamente uno de los argumentos que se esgrimen a nivel general contra la utilidad de la historia: su aparente inaplicabilidad. Es por ello necesario seguir profundizando en cómo construimos el discurso historiográfico y cómo lo proyectamos a la sociedad. Conviene en este punto que introduzcamos los planteamientos de Jürgen Kocka quien, además de su férrea defensa de la historia social crítica, considera que uno de los puntales sobre los que precisamente se apoya el valor social de la historia es en su carácter mediato.

28 HOBSBAWM, E., "Con la vista puesta en el mañana: la historia y el futuro", en Id., Sobre la historia, p. 68.

29 ABELOVE, H. et al. (eds.), op. cit., p. 16.

30 En palabras de Thompson, "The meaning is not there, in the process; the meaning is in what we make of the process", (ibid., p. 8).

31 Ibid., p. 6; HOBSBAWM, E., "El Grupo de Historiadores del Partido Comunista”, p. 68. 


\section{JÜRGEN KOCKA Y LA HISTORIA SOCIAL CRÍTICA ALEMANA}

Nacido en los Sudetes alemanes en 1941 y trasladado a la República Federal de Alemania a raíz de la reordenación del mapa europeo tras la Segunda Guerra Mundial, Kocka estudió historia en la Universidad Libre de Berlín, pasando posteriormente a ejercer docencia en la Universidad de Bielefeld para, finalmente, acabar recalando en la Universidad Libre en 1988. Durante los años noventa participó activamente en el seno del International Committee of Historical Sciences (ICHS), siendo presidente del mismo entre 2000 y 2005. Hasta 2007 fue también presidente del Wissenschaftsæentrums Berlin für Sozialforschung (Centro para la Investigación en Ciencia Social de Berlín). Sus temas de investigación siempre han tenido que ver con la historia social, entendiendo como tal la explicación del cambio social en base a las relaciones entre las estructuras y los procesos sociales, por un lado, y las experiencias y las acciones de los sujetos, por otro. Una historia, en todo caso, sustentada de forma esencial en el método comparado y en una explicación argumentativa que combina las perspectivas analítica y hermenéutica de la investigación histórica. Kocka ha escrito, desde estos presupuestos, numerosos trabajos sobre la autoridad en el mundo empresarial, sobre la historia política del movimiento obrero europeo, sobre la configuración y características de la sociedad burguesa en el siglo XIX y, desde 1989, a raíz de la caída del Bloque Soviético, sobre la crisis del socialismo real ${ }^{32}$.

El valor de Kocka como historiador sobrepasa, sin embargo, lo innegable de sus contribuciones a la historiografía sobre la Europa contemporánea. Entre otras cosas, porque constituye un acabado ejemplo

32 Tanto los datos sobre la trayectoria vital y académica de Jürgen Kocka como la temática de sus investigaciones están sacados de MILLÁN, J., "El contexto de la historia social crítica en la Alemania contemporánea", pp. 34-37, ensayo escrito como presentación a KOCKA, J., Historia social y conciencia histórica, Madrid, 2002, pp. 11-40. Para la concepción de historia social propia de Kocka han de verse los Capítulos II y III de esta última obra: "La historia social, ente la historia de las estructuras y la historia de las experiencias" y "¿El retorno a la narración? Alegato a favor de la argumentación histórica”, pp. 65-104. Sobre la metodología comparativa, ver el Capítulo I, "La comparación histórica", pp. 43-64, y "Comparison and Beyond", History and Theory, 42 (2003), pp. 39-44. La participación de Kocka en el International Committee of Historical Sciences y su elección como presidente del mismo en la Asamblea General del Congreso de Oslo, en ERDMANN, K. D., Toward a Global Community of Historians. The International Historical Congresses and the International Committee of Historical Sciences, 1898-2000, editado por J. KOCKA y W. J. MOMMSEN (New York/ Oxford, 2005). Más información sobre el ICHS en su página web: www.cish. org/index.htm [fecha de consulta: 21/01/2011]. De la obra de Kocka podemos destacar, además del ya citado Historia social y conciencia histórica, un par de volúmenes cuya principal virtud reside en recoger la traducción del alemán de algunos de sus trabajos fundamentales: Industrial Culture and Bourgeois Society. Business, Labor and Bureaucracy in Modern Germany, New York/ Oxford, 1999 y Civil Society and Dictatorship in Modern German History, Lebanon (New Hampshire), 2010. 
de la vitalidad intelectual del grupo de historiadores responsable de la renovación teórica y metodológica que la historiografía de la República Federal de Alemania protagonizó en los años sesenta y setenta del pasado siglo $^{33}$. Acabada la guerra, los historiadores que sobrevivieron a la catástrofe colaborando con el régimen nazi se convirtieron en las figuras dominantes del panorama académico del recién nacido Estado, postulando una historiografía social que introducía las estructuras y los procesos sociales en el análisis histórico. A pesar de ello, la masiva complicidad social de que disfrutó el nacionalsocialismo y la necesidad de asumir el pasado inmediato continuaban siendo temas tabú.

Esa misma necesidad acabaría convirtiéndose, precisamente, en el puntal sobre el que se construyó la propuesta de historia social crítica, consolidada a raíz de la fundación de la Universidad de Bielefeld a finales de los años sesenta y de la revista Geschichte und Gesellschaft en 1975, a la que Kocka se adscribe junto a otros como Hans-Ulrich Wehler, Wolfgang J. Mommsen o Hans-Jürgen Puhle. Si el impacto de la Segunda Guerra Mundial en las infancias de estos historiadores coadyuvó a que el pasado nazi fuera su punto de referencia intelectual por antonomasia, su anhelo profundo por construir una sociedad civil fuerte en torno al nuevo Estado democrático después del desastre de 1945 hizo para ellos inaplazable la cuestión de aclarar los vínculos entre el nacionalsocialismo y la sociedad alemana. Acometieron dicha tarea proponiendo una forma de hacer historia basada en la reflexión teórica y conceptual, en el diálogo abierto con la sociología, la economía y la politología y en el análisis de clases sociales o procesos generales como la industrialización. Una historia con vocación crítica, no para permanecer recluida en las aulas y en los despachos de la Universidad sino para ser debatida en el espacio público y los medios de comunicación, para fomentar el debate intelectual en el seno de la opinión nacional sobre el más próximo y conflictivo de los pasados imaginables. Una historia, en definitiva, en la que la denuncia de los costes sociales del pasado pudiera orientar la acción social hacia una organización racional de la sociedad.

En este contexto hemos de situar a Jürgen Kocka. En su caso concreto, el objetivo de construir una sociedad civil democrática, educada y culta, algo común entre los historiadores sociales críticos, conduce inexorablemente a la reivindicación de las funciones sociales de la historia. Para empezar, la historia ayuda a la explicación del presente como un producto del pasado y, con ello, a la resolución práctica de los problemas sociales. Porque para Kocka, si bien el conocimiento de la historia no es garantía de nada, no puede construirse una sociedad moderna sin él. Según sus propias palabras, "el conocimiento histórico $[\ldots]$ no conduce naturalmente de modo necesario

33 La evolución de la historiografía alemana que a continuación vamos a reseñar, en MILLÁN, J., op. cit., pp. 26-34 y en IGGERS, G. G., La ciencia bistórica en el siglo XX. Las tendencias actuales. Una visión panorámica y crítica del debate internacional, Barcelona, 1998, pp. 62-71. Sobre ello también puede verse BERNECKER, W. L., "La historiografía alemana reciente", Historia Contemporánea, 7 (1992), pp. 31-49. 
a una acción política racional, pero ésta supone a aquél necesariamente"34.

En el mismo sentido, en el de la contribución del estudio del pasado a la acción social del presente, Kocka defiende que la historiografía nos permite comprender fenómenos y procesos sociales del presente mediante la comparación y el contraste con fenómenos y procesos análogos del pasado. "La ciencia histórica puede procurar, partiendo de campos de objetos que no están demasiado «alejados» del presente - como para que resulten demasiado diferentes- pero que están lo suficientemente alejados -como para evitar al ocuparse con problemas del presente reservas y obturaciones que surgen fácilmente y dificultan la ilustración- categorías e intelecciones de carácter modélico que pueden servir para el conocimiento y la orientación en el presente social y político"35.

Ese papel de la historiografía en la acción social del presente no significa, en cualquier caso, el uso indiscriminado de la historia en la elaboración y difusión de discursos políticos. Dado que la historia, o mejor dicho, la memoria, constituye un elemento central en "la legitimación y estabilización de las relaciones sociales y políticas de dominación, en la justificación de las decisiones políticas, en la defensa de la crítica y en la fundamentación de la protesta", los historiadores deben asumir la empresa, no de acometer sin criterio "la mera destrucción de las respectivas tradiciones", pero sí la de ejercer un "control racional, científico", de unas "tradiciones manipuladas que [se] convierten demasiado fácilmente en mitos y leyendas que toman por su cuenta los interesados, amenazan al no conformista, inmunizan ante la crítica, irracionalizan [sic] la vida pública y adoctrinan a los ciudadanos", es decir, todo lo contrario al concepto de sociedad civil asumido por la historia social científica ${ }^{36}$.

Porque si los mitos y leyendas contribuyen a percibir el presente como la culminación del proceso histórico, como la meta a que conducía todo lo acontecido y ocurrido hasta entonces, la historiografía ofrece la posibilidad, según Kocka, de trascender el significado del presente para convertirlo en algo susceptible de transformación y para definir y delimitar el campo de acción de las personas y colectivos. Todo ello porque si los historiadores muestran "el presente social y político en su ser devenido y con ello en su capacidad de cambio" conseguirán "generar una actitud que acepte la realidad -que afrontamos masiva y forzosamente- no en su aparente necesidad sino que la comprenda en el transfondo [sic] de sus posibilidades aprovechadas y omitidas, pasadas y quizá aún existentes"37.

Lo cual no quiere decir, reincidimos, que la historia pueda constituir un recurso más en la legitimación de la acción política, sino que la

34 KOCKA, J., Historia social. Concepto. Desarrollo. Problemas, Barcelona, 1989, p. 174 (edición alemana original de 1986).

35 Ibid., p. 175.

36 Ibid., pp. 175-177.

37 Ibid., p. 177. 
historiografía proporciona orientación "de modo por cierto indirecto" a los sujetos del presente, ya sean individuales o colectivos, gracias a su "reserva de conocimientos, nociones, experiencias, motivaciones y normas", que en ningún caso deben producirse o proyectarse "con miras a fines específicos de orientación y acción" del mismo modo que "la historia no puede ser instrumentalizada y reducida sólo a las necesidades actuales". De hecho, ahí reside, para Kocka, la principal virtud de la historiografía, en el hecho de que no pueda servir a intereses inmediatos y directos: la conciencia histórica basa su función primordial de "instancia de crítica y revisión de los paradigmas dominantes de la acción política y social" en su propia "inutilidad inmediata" 38 .

Esta paradójica "inutilidad inmediata" consiste, sustancialmente y según Kocka, en que la historiografía -su investigación y su enseñanzaconforma, como ninguna otra ciencia social, el criterio de los ciudadanos y su capacidad de articular el pensamiento complejo. De este modo, la orientación que la historia proporciona a la acción social adquiere su significado concreto. El conocimiento de la historia facilita a los individuos y a los colectivos la posibilidad de tomar sus decisiones siempre teniendo en cuenta "la ambigüedad de la mayoría de las situaciones (que frecuentemente sólo pueden conocer realmente en la retrospectiva), de su multicausalidad e interdependencia, de la relatividad de las perspectivas, del propio peso del detalle y de las resistencias de la compleja realidad"; en definitiva, la historia permite aminorar el peligro inherente tanto a una "crítica total" de la realidad como a la "resignación que de ello resulta fácilmente", procurando mantener vivo el potencial de cambio que la historiografía posee intrínsecamente ${ }^{39}$.

Por lo tanto, Kocka se nos presenta como un historiador convencido de la calidad científica de su profesión y comprometido con la caracterización de la historiografía como un componente fundamental para cualquier sociedad civil democrática y culta. Para alcanzar una sociedad tal será imprescindible que el conocimiento histórico, metódico y riguroso, forme parte elemental de la reflexión que preceda a la práctica social y política de los actores individuales y/ o colectivos. Estos actores deberán tener muy presente lo que el conocimiento historiográfico proporciona a la sociedad para orientar sus movimientos en razón de la complejidad de todo fenómeno social, procurando denunciar los recursos culturales que fortalecen las relaciones sociales y políticas de dominación y asumiendo la percepción de cualquier realidad social como una entidad susceptible de transformación y cambio permanente.

38 Ibid., pp. 178-179.

39 Ibid., pp. 179-180. En última instancia, Kocka reconoce también la función de la historia "como objeto de diversión y de esparcimiento", misión que, si bien "no debería colocarse precisamente en el centro", tampoco debería considerarse cuestión de poca importancia (ibid., p. 180). 


\section{Consideraciones FinAles}

Hemos visto, por tanto, que los tres autores participan de un planteamiento básico: la necesidad de desarrollar una historia social crítica como base para la que es la contribución esencial de la historia a la sociedad, esto es, la noción de que el presente no es algo dado, sino que forma parte de un proceso inacabado y en continua transformación. La historiografía y la función social de la historia se encuentran indisolublemente ligadas. Esto deja abierta la cuestión de cuál es el medio adecuado en el que realizar esta historiografía crítica. A la vez, podemos preguntarnos qué ocurre con el sentido que le damos a la interpretación histórica y cómo la conciencia histórica se integra en la acción social. La pregunta escapa al objetivo inmediato de este artículo y presenta una complejidad extraordinaria. Ahora bien, en este sentido, creemos que es importante introducir un elemento de crítica esencial de cara al planteamiento de la función social de la historia que se ha delineado hasta ahora.

Los tres autores parten de un punto en común: la historia social crítica nos permite articular un pensamiento complejo mediante el que identificar los elementos que constituyen el potencial de cambio de una sociedad. Pero, en la medida en que la historia ofrece una aproximación particular al estudio de las sociedades humanas, ¿cuál es la contribución específica de la historia en ese proceso de transformación? Para Kocka, no existe otra disciplina con unas cualidades como las de la historiografía, que "puede, mejor que las ciencias sociales sistemáticas, educar para el pensamiento concreto" ${ }^{40}$. Hobsbawm, por su parte, señala que la historia centrada en la lucha de clases es un "valioso componente del movimiento obrero, ya que su tradición ideológica y su continuidad descansan en gran medida en la memoria colectiva de las viejas luchas" ${ }^{41}$. La historia cumpliría su función mediante su integración en la memoria del movimiento obrero, que le daría sentido $^{42}$. El conflicto o la contradicción en Hobsbawm surge cuando, desde la historiografía, nos preguntamos por qué la participación de la historia en la construcción de la memoria del movimiento obrero es legítima, pero no lo es en el caso de otro tipo de memorias. ¿No existe, en el fondo, un grado de instrumentalización política? ¿Qué legitima entonces uno u otro tipo de memoria social ${ }^{43}$ ?

La respuesta a esta pregunta se encuentra fuera del campo estrictamente

40 Ibid., p. 179 (énfasis del autor).

41 HOBSBAWM, E., "El Grupo de Historiadores del Partido Comunista”, p. 65.

42 HOBSBAWM, E. "¿Qué puede la historia decirnos sobre la sociedad contemporánea?”, p. 39.

43 FENTRESS, J. y WICKHAM, C., Social Memory, Oxford, 1992. 
historiográfico. Por lo tanto, si la validez del sentido que le damos a la historia reside no sólo en la práctica de un método reconocido como adecuado por la comunidad de historiadores ${ }^{44}$, sino en un juicio que se sitúa a otro nivel -como, siguiendo el ejemplo de Hobsbawm, el que legitima la lucha del movimiento obrero-, es necesario que nuestra práctica historiográfica sea susceptible de la misma crítica que pretendemos aplicar al resto de las relaciones sociales ${ }^{45}$. En definitiva, se trata de reconocer el carácter problemático y dialéctico del encuentro entre nuestras actitudes en el presente y el proceso histórico que estudiamos; de buscar que la experiencia -en el sentido que le daba Thompson- de nuestra práctica historiográfica, tenga repercusión sobre nuestro sistema de valores previo y, por ende, sobre nuestro planteamiento historiográfico de partida. Lo contrario, como decía Thompson, sería asumir que no existe problema al que no podamos dar respuesta dentro de nuestro propio marco de valores ${ }^{46}$. En definitiva, equivaldría a naturalizar dicho marco de valores y, a nivel historiográfico, eliminaría toda opción de problematizar nuestra metodología y el medio social en que desempeñamos nuestra labor como historiadores.

Precisamente, estos historiadores fueron exponentes de un proceso de renovación metodológica clave en la historia de la historiografía. Su contribución al giro cultural de la historia social se revela como una de sus aportaciones fundamentales. Por ejemplo y en síntesis, Kocka insistió en la necesidad de superar la persistente identificación que existía entre la historia estructural y la historia social, que impedía incorporar al análisis histórico factores de tanta relevancia como las acciones sociales y las experiencias culturales. En último término, estos historiadores contribuyeron a aportar una visión mucho más compleja y dinámica de los procesos sociales y elaborar, gracias también al diálogo con otras ciencias sociales, un esquema de análisis en el que era posible valorar el peso relativo de los diferentes factores sociales, tanto económicos como políticos y culturales.

Sus escuelas jugaron un papel fundamental en la renovación historiográfica de los años sesenta y setenta, momento en el que sus preocupaciones se proyectaron más allá de los reducidos círculos iniciales, promoviendo la crítica y superación de los planteamientos académicos preponderantes hasta entonces. Sin embargo, no podrían haber desempeñado este rol de no haber sido por la posición académica en que llegaron a encontrarse la mayoría de sus integrantes. Incluso Thompson, quien rechazó incorporarse plenamente a la academia, hizo uso de los recursos de los que ésta le podía proveer, como las mismas clases o la posibilidad de publicar en medios tan influyentes como Past \& Present. Tal proceso de renovación fue

44 Una sistematización de los parámetros legitimados por la historiografía para la salvaguarda de su profesionalidad y objetividad, en KOCKA, J., op. cit., pp. 57-64.

45 Crítica que para Thompson tiene un componente moral fundamental. Vid. THOMPSON, E. P., "William Morris", en Id., Agenda para una historia radical, Barcelona, 2000, p. 123. 46 ABELOVE, H. et al. (eds.), op. cit., p. 8. 
un proceso largo y difícil. Hobsbawm, como vimos, narraba las dificultades a las que se tuvieron que enfrentar los historiadores marxistas en un medio académico hostil a aceptar sus propuestas ${ }^{47}$, pero, a la vez, esta singularidad metodológica y teórica constituía un capital científico con el que pugnaban por abrir brecha en las estructuras de la universidad.

Kocka se encontró en una situación similar. Los historiadores que habían colaborado con el régimen nazi habían mantenido sus puestos en las universidades y eran ellos mismos promulgadores de una historia social que se encontraba en un estadio aún anterior a este giro cultural. Además, Alemania se encontraba aún en proceso de hacer frente a ciertas preguntas fundamentales sobre los vínculos entre el nazismo y la sociedad alemana. Realizar estas preguntas tenía un valor esencial en el proceso de construcción de una nueva sociedad civil y a la vez hizo de los historiadores que las plantearon referentes no sólo académicos, sino públicos, ya que gozaron de una presencia mediática que no era equiparable a la que podían tener sus colegas británicos. En cualquier caso, y a pesar de las diferencias, la práctica historiográfica de estos historiadores se desarrolló en un medio inicialmente adverso que luego, a partir de un cierto momento, llegaron a dominar. Y aunque temas como el colaboracionismo con los nazis no sólo tuvieran una vocación social, sino que fueran importantes recursos de capital científico, debemos recordar que abrirse un hueco en la Universidad tenía un valor mucho mayor que el puramente académico para historiadores que, como Hobsbawm, consideraban el ámbito universitario como el único espacio verdaderamente libre para el ejercicio de la crítica.

Ahora bien, ¿era, o es, éste un ámbito suficiente para el pleno desarrollo del potencial del historiador como actor social? Porque en el caso de Kocka, por ejemplo, la reivindicación del papel social de la historiografía apareció en su agenda precisamente en el momento en que la sociedad alemana comenzaba a dar la espalda a los historiadores. El interés por la historia y la conciencia histórica de los alemanes disminuyeron con fuerza a lo largo de las décadas de 1960 y, sobre todo, de 1970, en la misma medida en que el languidecimiento del debate público sobre el pasado nazi devolvía a los historiadores a la Universidad. En este contexto cultural se comprende, en toda su naturaleza, el esfuerzo asumido por la historia social crítica de asentar con decisión el estatuto científico de una historiografía que sufría un acelerado reflujo, desprestigiada socialmente y con nula ascendencia sobre la opinión pública, la misma que anteriormente había solicitado sus oficios para aclarar lo que había pasado entre 1933 y 1945. En otras palabras, la defensa de las funciones sociales de la historiografía por parte de los historiadores sociales críticos aparece inextricablemente unida a la pretensión de trascender el escenario estrictamente académico, al que se han visto recluidos después de esa edad de oro en que ocuparon el espacio público reclamados por los ciudadanos. Implícitamente, por lo tanto, juzgan

47Ibid., p. 30. 
a la Universidad como un ámbito insuficiente.

El problema que nos encontramos hoy, al menos en la Universidad española, es que no sólo es quizá un ámbito que imponga barreras a la proyección de la historia social crítica, sino que incluso sufre aún limitaciones estructurales que determinan en extremo la capacidad de producir una historiografía que cumpla con esa función social crítica.

Su desarrollo durante los últimos cuarenta años, los de la democracia, permite reconocer dos condicionantes de singular relevancia. Por un lado, la influencia de las administraciones locales y regionales en la elección de los objetos de estudio; por otro, la persistencia de estructuras académicoadministrativas patrimonialistas. Esto último, según José Antonio Piqueras, tiene consecuencias perversas para la configuración de una historiografía crítica porque coarta los debates teóricos y metodológicos en el seno de la Universidad. Esas estructuras, cuya unidad básica para la investigación y la docencia son las áreas de conocimiento, funcionan según mecanismos internos de cooptación, lo cual conlleva de forma inherente una fuerte carga de coacción a la hora del saludable ejercicio de la autocrítica. Por tanto, si el porvenir de las carreras investigadoras está sujeto al juicio de los profesores funcionarios, el continuo diagnóstico del trabajo realizado, una de las palancas fundamentales para el desarrollo de las historiografías modernas, se convierte en una arriesgada aventura, entre otras cosas, por la frecuencia con que una mera "discusión de ideas" es interpretada como un verdadero "cuestionamiento profesional" 48 .

Por si fuera poca cosa, la historiografía académica se encuentra cada vez más sometida a los dictámenes del poder político, ya sea a través del control de los mecanismos de evaluación, ya de los intereses de quienes se encargan de la gestión de los recursos públicos. Todo ello por no hablar de la creciente penetración del interés y la lógica de gestión empresarial -encubierta muchas veces bajo los términos "calidad" y "competitividad"que no sólo minan los espacios de auténtica libertad en el ejercicio de la docencia y de la investigación, sino que incluso condicionan la transferencia ${ }^{49}$ de conocimiento desde la Universidad a la sociedad ${ }^{50}$. Ante esta perspectiva, los historiadores deben participar en la recuperación de la Universidad como un

48 PIQUERAS, J.A., "El abuso del método, un asalto a la teoría", en CASTILLO, S. (coord.), La Historia Social en España. Actualidad y perspectivas. Actas del I Congreso de la Asociación de Historia Social. Zaragoza, septiembre, 1990, Madrid, 1991, pp. 89-91. Sobre estos mismos problemas, vid. CRIADO BOADO, F. "Ocho observaciones", Revista d'Arqueologia de Ponent, 20 (2010) (n $\mathrm{n}^{\circ}$ monográfico titulado Hacia una carrera investigadora en arqueología), p. 269. 49 CASTRO MARTÍNEZ, E.; FERNÁNDEZ DE LUCIO, I.; PÉREZ MARÍN, L. y CRIADO BOADO, F., "La transferencia de conocimientos desde las humanidades: posibilidades y características”, Arbor. Ciencia, Pensamiento y Cultura, CLXXXIV: 732 (2008), pp. 619-636. 50 Sobre esto ha escrito en este mismo foro PÉREZ MIRANDA, I., "El futuro del pasado. Una perspectiva crítica desde la Universidad de Salamanca”, El futuro del pasado, 1 (2010), pp. 69-70. 
espacio auténticamente público y libre de las relaciones internas de dominación, ya que de lo contrario comprometen la base misma de su actividad.

En cuanto a su proyección, ¿qué otras posibilidades hay? Un ejemplo lo constituye la asociación Libertépour l'bistoire, presidida por Pierre Nora, que se fundó ante el abuso que suponían ciertas leyes de memoria aprobadas en distintos países. En su Appel de Blois, varios signatarios, entre ellos el propio Hobsbawm, recordaban que la historia no puede ser esclava de la actualidad; que no corresponde a ninguna autoridad política definir la verdad histórica ni restringir la libertad del historiador bajo la amenaza de sanciones penales -cosa que, efectivamente, ha llegado a ocurrir ${ }^{51}$-; y hacían un llamamiento a los historiadores para que unieran sus fuerzas dentro de sus propios países y crearan estructuras similares a Liberté pour l'bistoire ${ }^{52}$. Dentro de nuestro contexto, ¿qué mecanismos y recursos tenemos para crear estructuras ajenas a las propiamente universitarias? ¿Qué sentido podemos darle a esta actividad? ¿Es legítima la participación del historiador, como historiador, en estructuras ajenas al campo historiográfico? Como señalamos al principio, la historia tiene hoy a su alcance una gran diversidad de medios a través de los que difundir y transferir el conocimiento histórico, pero esto no significa que todos sean igualmente válidos ni que las estrategias empleadas sean las adecuadas. Por ejemplo, la participación del historiador en los medios de comunicación no puede ir desligada de una consideración crítica de los mismos, ya que no constituyen canales neutros de transmisión de información. Iniciamos este artículo con una crítica al contenido historiográfico que encontramos en los medios actuales. Esto nos ha llevado a replantear el tipo de historiografía que creemos necesario transmitir. Debemos, desde aquí, plantearnos cuáles son los medios adecuados para ello.

Se trata de preguntas que dejaremos abiertas; preguntas que conllevan una reflexión específica sobre las estrategias adecuadas para hacer llegar a la sociedad lo que, en definitiva, constituye la propuesta esencial de los autores que hemos tratado: que la historia nos da la capacidad de desnaturalizar el presente para así trascenderlo. Sólo desde esta perspectiva la historia adquiere pleno potencial como disciplina crítica, en tanto que nos enseña que la realidad del presente es transformable y nos ayuda a valorar en qué medida nuestra acción puede contribuir a ello.

51 Véase el artículo de GARTON ASH, T., "La necesidad del debate histórico", en El País, 19/10/2008 (http://www.elpais.com/articulo/opinion/necesidad/debate/historico/elpe pusocdgm/20081019elpdmgpan 1/Tes [Fecha de consulta: 20/02/2011]).

52 El llamamiento se puede consultar en la página web de la asociación: http://www.lphasso.fr/ [Fecha de consulta: 20/02/2011]. 
